\title{
Comparison Ability of Polymers Acrycoat S100 and HPMC K4M to Entrapment Efficiency Domperidone in Microspheres
}

\author{
Pratiwi Apridamayanti, Nora N.Sinaga*, Rise Desnita \\ Pharmacy Study Programme, Faculty of Medicine, Universitas Tanjungpura, Pontianak - Indonesia
}

Submitted 24 August 2018; Revised 22 January 2019; Accepted 21 August 2019; Published 03 February 2020

*Corresponding author: noranurlina@gmail.com

\begin{abstract}
Domperidone is a prokinetic and antiemetic agent which has low bioavaibility. To increase the bioavaibility of drug, it can be modified into microsphere that can hold drug more longer in gastric to improve the bioavaibility. The microsphere preparation requires a polymer that can make matrix system to protect and deliver the drugs. Acrycoat S100 and HPMC K4M are the usual polymers that used for encapsulation and have biodegradable characteristic. The aim of this research is to know the comparison ability of two different polymers to entrapment the drug in microsphere. Microsphere domperidone made by solvent evaporation method in 6 formula. F1, F2 and F3 using $50 \mathrm{mg}, 100$ $\mathrm{mg}$ and $150 \mathrm{mg}$ Acrycoat S100 polymer, while F4, F5 and F6 using $50 \mathrm{mg}, 100 \mathrm{mg}$ and $150 \mathrm{mg}$ HPMC K4M polymer. The tests were conducted by the determination of the percentage of entrapment efficiency using UV spectrophotometer and evaluation of organoleptic, particle measurement and surface microsphere morphology. The results showed that F3 with Acrycoat S100 polymer has a greater entrapment efficiency of $78,712 \% \pm 4,260 \%$ compared to the highest percentage efficiency of HPMC K4M polymer of 4,734 $\pm 0,390$.
\end{abstract}

Keywords: Acrycoat S100, domperidone, entrapment efficiency, HPMC K4M, microsphere

\section{Perbandingan Kemampuan Polimer Acrycoat S100 dan HPMC K4M terhadap Efisiensi Penjerapan Domperidon dalam Microsphere}

\begin{abstract}
Abstrak
Domperidon merupakan agen prokinetik dan antiemetik yang memiliki bioavaibilitas rendah. Salah satu upaya untuk meningkatkan bioavaibilitas obat dilambung adalah dengan sistem sediaan microsphere yang dapat menahan obat lama berada di lambung sehingga dapat meningkatkan bioavaibilitasnya. Sediaan microsphere membutuhkan polimer yang dapat menjadi sistem matriks untuk melindungi dan menghantarkan obat. Acrycoat S100 dan HPMC K4M merupakan polimer yang sering digunakan dalam enkapsulasi dan bersifat biodegradable. Penelitian ini bertujuan untuk mengetahui perbandingan kemampuan dua jenis polimer berbeda terhadap efisiensi penjerapan domperidon dalam sediaan microsphere. Microsphere domperidon dibuat dengan menggunakan metode penguapan pelarut (solvent evaporation) dalam enam formula berbeda dengan F1, F2 dan F3 menggunakan polimer Acrycoat S100 sebanyak $50 \mathrm{mg}, 100 \mathrm{mg}$ dan $150 \mathrm{mg}$, sedangkan F4, F5 dan F6 menggunakan polimer HPMC K4M sebanyak $50 \mathrm{mg}, 100 \mathrm{mg}$ dan $150 \mathrm{mg}$. Pengujian yang dilakukan yaitu penetapan kadar persen efisiensi penjerapan dengan menggunakan spektrofotometer UV dan evaluasi sediaan berupa organoleptik, pengukuran partikel dan morfologi permukaan microsphere. Hasil penentuan efisiensi penjerapan menunjukkan polimer Acrycoat S100 F3 memiliki efisiensi penjerapan yang lebih besar yaitu $78,712 \% \pm 4,260 \%$ dibandingkan dengan persen efisiensi penjerapan terbaik dari polimer HPMC K4M yaitu sebesar 4,734 $\pm 0,390$.
\end{abstract}

Kata Kunci: Acrycoat S100, domperidon, efisiensi penjerapan, HPMC K4M, microsphere. 


\section{Pendahuluan}

Domperidon merupakan antagonis reseptor dopamin D2 yang digunakan sebagai agen prokinetik dan antiemetik pada pengobatan gastroparesis, mual dan muntah. ${ }^{1}$ Domperidon memiliki kelarutan yang buruk dalam air $(0,986 \mathrm{mg} / \mathrm{L})$ dan bioavaibilitas rendah yang dilaporkan berkisar $13-17 \%{ }^{2}$ Obat ini memiliki kelarutan yang baik pada $\mathrm{pH}$ asam tetapi menurun secara signifikan pada $\mathrm{pH}$ basa. Saat berada pada cairan intestinal, bentuknya dalam dosis oral pelepasan terkendali dapat menyebabkan obat ini mengendap dalam formulasinya karena kelarutannya yang buruk pada $\mathrm{pH}$ basa. Obat yang mengendap tidak mampu dilepaskan dari formulasinya. ${ }^{3}$ Hal ini menyebabkan rendahnya bioavaibilitas domperidon sehingga cocok untuk dibuat dalam bentuk sediaan yang bertujuan mempertahankan obat lama berada di lambung untuk meningkatkan bioavaibilitasnya.

Microsphere merupakan bagian dari penghantaran obat baru yang sangat potensial dalam sistem penghantaran obat. ${ }^{4}$ Microsphere didefinisikan sebagai mikropartikel sferis dengan diameter antara 1-1000 $\mu \mathrm{m}$. Teknik preparasi microsphere menawarkan berbagai peluang untuk mengontrol aspek administrasi obat dan meningkatkan efek terapeutik ke sisi target dengan cara sustained control release. ${ }^{5}$ Mikropartikel dapat menjadi penghantaran obat yang akurat, mengurangi konsentrasi obat pada target dan memberikan sistem penghantaran yang efektif untuk zat aktif yang sedikit larut dalam air. Mikropartikel juga dapat meningkatkan bioavaibilitas obat dan memiliki kemampuan baik dalam mengurangi frekuensi pemberian dan menurunkan toksisitas beberapa obat. ${ }^{6-8}$

Peningkatan konsentrasi polimer diketahui dapat meningkatkan efisiensi penjerapan obat dalam floating microspheres. ${ }^{9}$ Hidroksipropilmetil selulosa (HPMC) dan Acrycoat merupakan polimer yang sering digunakan dalam enkapsulasi. Keduanya diketahui bersifat biodegradable sehingga dapat digunakan untuk farmasetik. HPMC merupakan polimer polisakarida turunan selulosa yang larut dalam air, sedangkan acrycoat termasuk dalam polimer latek dan dispersi. ${ }^{10}$

Penelitian ini bertujuan untuk mengetahui perbandingan kemampuan dua jenis polimer berbeda yaitu Acrycoat S100 dan HPMC K4M terhadap efisiensi penjerapan Domperidon dalam microsphere.

\section{Metode}

2.1. Alat

Peralatan gelas (Pyrex Iwaki $\left.{ }^{\circledR}\right)$, neraca digital (Precisa TYP 320-9410-003), hotplate (Schott Instrument ${ }^{\circledR}$ ), termometer, mortir dan stamper, mikropipet (CAPP), mikroskop optik, object glass, cover glass, magnetik stirer, desikator, dan spektrofotometer UVVIS (Shimadzu 2450).

2.2. Bahan

Domperidon (Dexa Medica), Acrycoat (Corel Pharm Chem), HPMC K4M (Shanghai Honest Chem), diklorometana (DCM), etanol, poli vinil alkohol (PVA), span 80, aquades, parafin cair, petroleum ether dan metanol (Merck).

\subsection{Prosedur Rinci}

\subsubsection{Pembuatan Microsphere Domperidon}

Microsphere Domperidon dibuat menggunakan metode emulsion solvent evaporation. Domperidon dan polimer dilarutkan dalam pelarut diklorometana:etanol (1:1). Pada pembuatan microsphere domperidon dengan polimer Acrycoat S100, larutan domperidon dan polimernya didispersikan dalam aquades mengandung PVA, sedangkan microsphere domperidon dengan menggunakan polimer HPMC K4M didispersikan dalam parafin cair mengandung span 80. Campuran diaduk menggunakan magnetic stirer dengan kecepatan $500 \mathrm{rpm}$ selama 2 jam. Microsphere yang terbentuk disaring dengan kertas saring Whatman no 42 dan dicuci hingga 3-4 kali dengan aquades untuk microsphere domperidon dengan polimer Acrycoat S100, dan dengan petroleum eter untuk microsphere domperidon dengan polimer HPMC K4M. Microsphere domperidon dengan polimer Acrycoat S100 dikeringkan dalam desikator selama 
sehari semalam, sedangkan microsphere domperidon dengan polimer HPMC K4M di suhu ruang semalaman. Formula dapat dilihat pada Tabel 1.

\subsubsection{Penentuan Efisiensi Penjerapan}

Ditimbang sejumlah microsphere dan digerus halus dalam mortar. Serbuk microsphere dilarutkan dalam metanol. Larutan diukur dengan menggunakan spektrofotometer UV pada panjang gelombang maksimum. Persen efisiensi penjerapan dihitung dengan menggunakan rumus:

$\% \mathrm{EE}=\frac{\text { kadar obat terukur dalam microspheres }}{\text { kadar awal obat }} \times 100 \%$

\subsubsection{Pengamatan Organoleptik}

Pemeriksaan organoleptik meliputi bentuk, warna dan bau pada suhu ruang. Pemeriksaan warna dan bau dilakukan melalui panca-indra, sedangkan pemeriksaan bentuk dilakukan dengan mikroskop optik. Pengamatan dilakukan sekali terhadap masing-masing hasil formula selama 1-2 menit.

\subsubsection{Penentuan Ukuran Partikel}

Penentuan ukuran partikel mirosphere dilakukan menggunakan mikroskop optik. Sejumlah microsphere domperidon dengan polimer Acrycoat S100 diletakkan pada kaca objek dan didispersikan dengan beberapa tetes aquades. Sedangkan microsphere domperidon dengan polimer HPMC K4M diletakkan pada kaca objek dan didispersikan dengan olive oil. Microspheres domperidon dilihat dibawah mikroskop.
2.3.5. Pengamatan Morfologi Permukaan

Microsphere Domperidon

Pengamatan morfologi permukaan microsphere Domperidon dilakukan menggunakan Scanning Electron Microscopy (SEM). Sejumlah microspheres ditempatkan pada sample stub dan di-coating dengan gold (emas) dibawah vakum dengan menggunakan sputter coater. Sampel dianalisis dengan scanning electron microskop.

\subsubsection{Pembuatan Larutan Stok}

Domperidon memiliki kelarutan yang sangat buruk di air sehingga pelarut organik dibutuhkan untuk melarutkan obat. Larutan stok domperidon $(100 \mu \mathrm{g} / \mathrm{mL})$ dibuat dengan melarutkan $10 \mathrm{mg}$ domperidon yang ditimbang akurat dalam metanol $100 \mathrm{~mL}$. Campuran diaduk hingga homogen.

\subsubsection{Pengukuran Panjang Gelombang} Maksimum

Pengukuran panjang gelombang maksimum domperidon dilakukan dengan pengukuran larutan sampel dari rentang panjang gelombang 200-400 $\mathrm{nm}$.

\subsubsection{Pembuatan Kurva Baku}

Seri kadar dibuat dari larutan stok sebanyak 6 seri kadar diantaranya 8, 12, 16, 20 dan $24 \mu \mathrm{g} / \mathrm{mL}$. Diukur absorbansinya dengan spektrofotometer UV-Vis pada panjang gelombang maksimum.

\section{Hasil}

3.1. Karakterisasi Organoleptik Microsphere Domperidon

Pengamatan organoleptis microsphere

Tabel 1. Formula microsphere domperidon

\begin{tabular}{cccccccc}
\hline No. & Bahan & \multicolumn{7}{c}{ Jumlah } \\
\cline { 3 - 7 } & & F1 & F2 & F3 & F4 & F5 & F6 \\
\hline 1. & Domperidon (mg) & 50 & 50 & 50 & 50 & 50 & 50 \\
2. & Acrycoat S100 (mg) & 50 & 100 & 150 & - & - & - \\
3. & PVA (mg) & 50 & 50 & 50 & - & - & - \\
4. & Aquades (ml) & 100 & 100 & 100 & - & - & - \\
5. & HPMC K4M (mg) & - & - & - & 50 & 100 & 150 \\
6. & Span 80 (ml) & - & - & - & 2 & 2 & 2 \\
7. & Paraffin cair (ml) & - & - & - & 100 & 100 & 100 \\
\hline
\end{tabular}


domperidon yang dilakukan meliputi bentuk, bau dan warna. Pengamatan yang dilakukan dengan panca indra menunjukkan hasil microsphere domperidon dengan polimer Acrycoat S100 berupa serbuk putih halus dan tidak berbau sedangkan pada microsphere domperidon dengan polimer HPMC K4M berupa serbuk putih kasar dan tidak berbau yang dapat dilihat pada Gambar 1.

\subsection{Penentuan Ukuran Partikel}

Pengukuran ukuran partikel microspheres domperidon dilakukan dengan menggunakan mikroskop optik. Ukuran microsphere domperidon yang didapatkan dengan polimer Acrycoat S100 memiliki rentang 31,88 - 319,87 $\mu \mathrm{m}$, sedangkan dengan polimer HPMC K4M memiliki rentang 83,68 $-218,22 \mu \mathrm{m}$.

\subsection{Morfologi Permukaan Microsphere Domperidon}

Analisis SEM dilakukan untuk mengetahui morfologi dari microsphere domperidon. Perbesaran yang digunakan pada pengamatan adalah perbesaran 400 kali. Hasil analisis SEM dapat dilihat pada Gambar 2.

\subsection{Panjang Gelombang Maksimum}

Penentuan panjang gelombang maksimum domperidon dalam metanol dilakukan menggunakan spektrofotometri UV pada konsentrasi $8 \mathrm{ppm}$ dan rentang panjang gelombang 250-300 $\mathrm{nm}$. Diperoleh panjang gelombang maksimum domperidon dalam metanol ialah $286,5 \mathrm{~nm}$. Ini mendekati dengan penelitian sebelumnya yaitu 287,2 nm. ${ }^{11}$

\subsection{Efisiensi Penjerapan Domperidon dalam Microsphere \\ Hasil efisiensi penjerapan kedua} polimer dapat dilihat pada Tabel 2.

\section{Pembahasan}

Dari Gambar 2 morfologi permukaan microsphere Domperidon dengan SEM, terlihat bahwa microsphere domperidon dengan kedua polimer memiliki bentuk yang sferik dan berukuran $172,9 \mu \mathrm{m}$ pada microsphere domperidon dengan polimer Acrycoat S100 serta 218,22 $\mu \mathrm{m}$ pada microsphere domperidon dengan polimer HPMC K4M. Microsphere domperidon dengan polimer HPMC K4M memiliki morfologi permukaan yang lebih halus dibandingkan microsphere domperidon dengan polimer Acrycoat S100. Microsphere domperidon dengan polimer Acrycoat S100 terlihat memiliki morfologi permukaan yang bercelah, retak dan keropos. Kondisi permukaan yang retak dan keropos ini dapat membantu dalam pelepasan obat karena dapat memfasilitasi penetrasi dari medium pelarut ke dalam microsphere. Morfologi permukaan yang lebih kasar dapat meningkatkan kontak dengan agen pembasahnya dibandingkan dengan morfologi permukaan yang lebih halus. ${ }^{12}$

Hasil persen efisiensi penjerapan pada kedua polimer sangat berbeda signifikan. Persentase efisiensi penjerapan domperidon dalam microsphere ditemukan paling optimum pada konsentrasi polimer terbesar pada masing-masing polimer (F3 dan F6). Semakin meningkat jumlah polimer yang digunakan, persentase efisiensi penjerapan
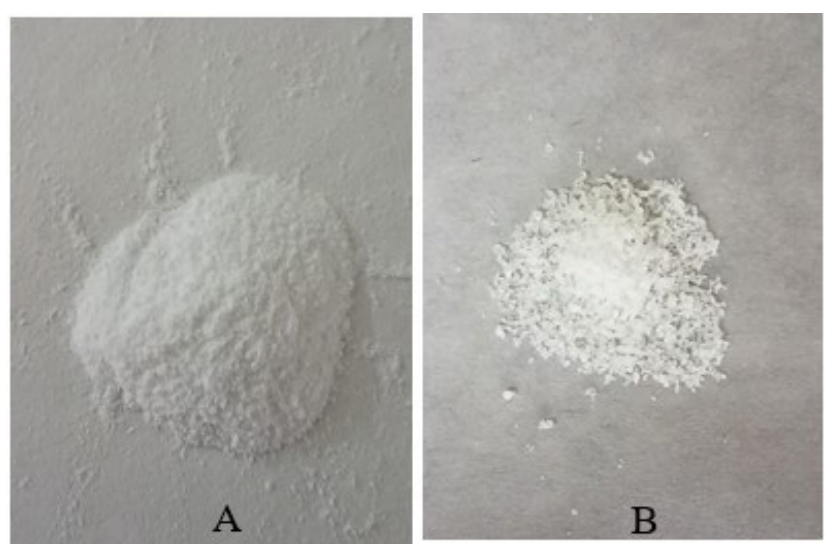

Gambar 1. Microsphere Domperidon dengan Polimer Acrycoat S100 (A) dan HPMC K4M (B) 

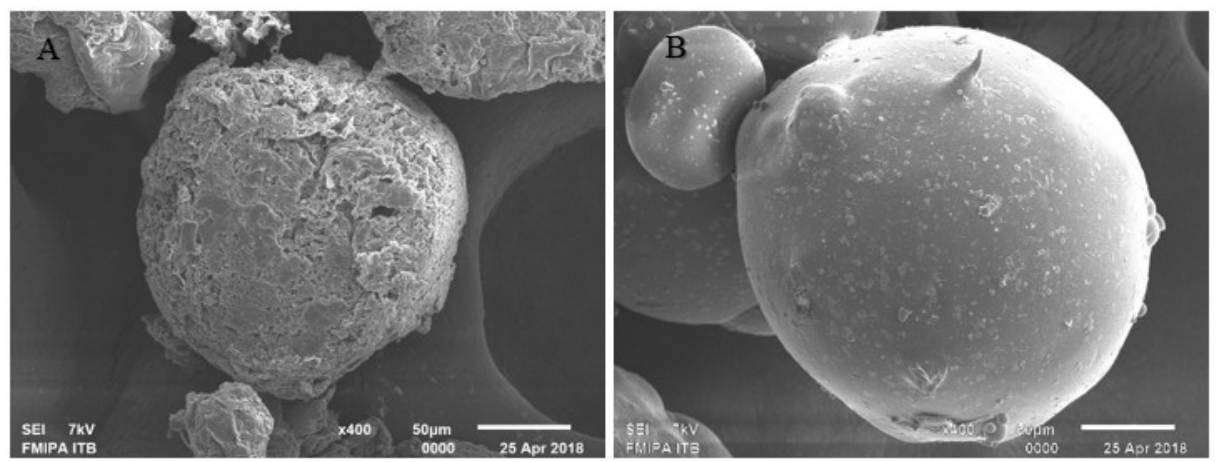

Gambar 2. Pengamatan SEM pada microsphere domperidon dengan polimer crycoat S100 (A) dan polimer HPMC K4M (B)

terlihat semakin meningkat pula. Hal ini sesuai dengan penelitian lain yang mengatakan bahwa peningkatan jumlah polimer yang digunakan dapat meningkatkan persentase efisiensi penjerapan zat aktif obat dalam microsphere. Hal ini disebabkan peningkatan konsentrasi polimer dapat meningkatkan kapasitas penjerapan obat. $^{13}$ Persentase efisiensi penjerapan terbaik dari polimer Acrycoat S100 dan HPMC K4M kemudian diuji secara statistik dengan menggunakan uji Independent Samples T-Test. Dari nilai signifikan uji $\mathrm{T}$-test $\leq 0,05$ menunjukkan adanya perbedaan signifikan pada persentase efisiensi penjerapan domperidon dalam microsphere dengan menggunakan polimer Acrycoat S100 dan HPMC K4M. Polimer Acrycoat S100 dapat menjerap domperidon lebih baik dan lebih besar dibandingkan dengan polimer HPMC K4M. Hal ini berarti efisiensi penjerapan domperidon dalam sediaan microsphere lebih optimum menggunakan polimer Acrycoat S100 daripada menggunakan polimer HPMC K4M.

Rendahnya efisiensi penjerapan oleh microsphere Domperidon dengan polimer HPMC K4M dapat disebabkan oleh beberapa hal. Pada proses pembentukan microsphere, droplet dengan ukuran lebih besar memerlukan waktu pengerasan atau pemadatan menjadi microsphere yang lebih lama sehingga obat akan cenderung berdifusi menuju fase kontinyu dan menyebabkan penurunan nilai kadar obat. ${ }^{14}$ Polimer HPMC K4M lebih viskos dibandingkan dengan polimer Acrycoat S100 sehingga cenderung membuat ukuran droplet yang lebih besar pada saat proses pembentukan microsphere. Selain itu sifat hidrofilitas zat aktif dan fase kontinyu yang sama dapat menyebabkan terjadinya proses difusi zat aktif melewati matriks polimer menuju fase kontinyu sesaat setelah penguapan perlarut dan pembentukan microsphere. ${ }^{15,16}$ Faktor lainnya ialah dapat disebabkan oleh ketidakcocokan formula microspheres yang dibuat dari HPMC sehingga perlu untuk dilakukan uji pemilihan formula microsphere dengan HPMC yang baik.

Microsphere domperidon dengan polimer HPMC K4M dikeringkan dengan perlakuan yang berbeda daripada polimer Acrycoat S100 karena pada pembuatannya polimer HPMC K4M menggunakan petroleum ether untuk mencuci microspheres sehingga perlu untuk diuapkan di ruang terbuka dan cukup dengan suhu ruang untuk mengeringkannya karena petroleum ether mudah menguap, sedangkan microspheres domperidon dengan polimer acrycoat yang menggunakan aquades pada pencucian akhirnya memerlukan desikator dalam

Tabel 2. Hasil persentase efisiensi penjerapan domperidon dalam sediaan microsphere

\begin{tabular}{ccccccc}
\hline \multirow{2}{*}{ Jumlah } & \multicolumn{3}{c}{ \% EE Polimer Acrycoat S100 } & \multicolumn{3}{c}{ \% EE Polimer HPMC K4M } \\
\cline { 2 - 6 } Polimer & F1 & F2 & F3 & F4 & F5 & F6 \\
\hline $50 \mathrm{mg}$ & $58,018 \pm 6,841$ & & & $0,497 \pm 0,089$ & & \\
$100 \mathrm{mg}$ & & $63,820 \pm 7,813$ & & & $3,707 \pm 0,446$ & \\
$150 \mathrm{mg}$ & & & $78,712 \pm 4,260$ & & & $4,734 \pm 0,390$ \\
\hline
\end{tabular}


pengeringannya. Hasil akhir yang penting dicapai ialah seluruh formula dari kedua polimer dapat benar-benar kering sehingga dapat terbebas dari faktor lain yang mungkin mempengaruhi hasil pengujian. Hasil akhir microspheres yang siap dilakukan pengujian (microspheres sudah kering) ditandai dengan konstannya berat microspheres yang diperoleh pada setiap formula.

\section{Simpulan}

Microspheres Domperidon yang dibuat dengan metode penguapan pelarut menggunakan polimer Acrycoat S100 memiliki persen efisiensi penjerapan yang lebih besar dibandingkan dengan polimer HPMC K4M.

\section{Daftar Pustaka}

1. Ahmad N, Ferris JK, Gooden E, Abell T. Making a case for domperidone in the treatment of gastrointestinal motility disorders. Curr. Opin. Pharmacol. 2006; 6: 571-576.

2. Reena T, Vandana D. Enhancement of solubility and dissoultion rate of domperidone using cogrinding and kneading technique. J Drug Deliv. Therap. 2012;2(4):152-158

3. Patel K, Jain PK, Baghel R, Tagde P, Patil A. Preparation and in vitro evaluation of a microballoon delivery system for domperidone. Der pharmacia lettre. 2011;3(6):131-141

4. Parida KR, Panda SK, Ravanan P, Roy H, Manickam M, Talwar P. Microparticles based drug delivery systems: preparation and application in cancer therapeutics. Int Arch Appl Sci Technol. 2008;4(3):68-75

5. Kataria S, Middha A., Sandhu P, Ajay B, Bhawana K. Microsphere: A review. Inter J Res Pharm Chem. 2011;1(4):1184-98.

6. Parida KR, Kumar S, Ravanan P, Roy H, Manickam M, Talwar P. Microparticles based drug delivery systems: preparation and application in cancer therapeutics. International archive of applied sciences and technology IAAST. 2013;4(3):68-75

7. Ozeki, T., Kano, Y., Takahashi, N. et al. Improved Bioavailability of a Water-
Insoluble Drug by Inhalation of DrugContaining Maltosyl- $\beta$-Cyclodextrin Microspheres Using a Four-Fluid Nozzle Spray Drier. AAPS PharmSciTech. 2012; 13: $1130-37$

8. Afzal Hussain, Abdus Samad, Mohd Usman Mohd Siddique and Sarwar Beg, "Lipid Microparticles for Oral Bioavailability Enhancement", Recent Patents on Nanomedicine. 2015 5: 104.110.

9. Shinde SV, Pawar R, Joshi HP. Domperidone Floating Microspheres: Formulation And In Vitro Evaluation. Journal of Pharmacy Research. 2012;5(4): 2235-2238

10. Agoes G. Enkapsulasi farmasetik. Bandung: Penerbit ITB; 2010

11. Javali B, Sravanthi B, Mohan R B, Gopi K, Vamsi K,et al. Development and Validation of UV Spectrophotometric Method for Simultaneous Estimation of Omeprazole and Domperidone in Capsule Dosage forms. Glob J Pharmaceu Sci. 2017; 1(2): 555-560.

12. Arefin P, Hasan I, Reza MS. Design, characterization and in vitro evaluation of HPMC K100 M CR loaded Fexofenadine $\mathrm{HCl}$ microsphere. Springer Plus. 2016;5:691

13. Jelvehgari, Mitra, and Seyed Hassan Montazam. "Comparison of microencapsulation by emulsion-solvent extraction/evaporation technique using derivatives cellulose and acrylatemethacrylate copolymer as carriers." Jundishapur J Nat. Pharmac. Prod.. 2012; 7(4): 144-52.

14. ChellaN,YadaKK, VempatiR.Preparation and Evaluation of Ethyl Cellulose Microsphere Containing Diclofenac Sodium by Novel w/o/o Emulsion Method. Journal of Pharmaceutical Sciences and Research.2010:884-888

15. Muhaimin. Study of microparticle preparation by the solvent evaporation method using focused beam reflectance measurement (FBRM) (disertasi). Universitas Berlin; 2013 